\title{
Parametric studies of dissimilar welding of AISI 409 ferritic stainless steel to AISI 316 L austenitic stainless steel using Taguchi desirability analyses
}

\author{
${ }^{1}$ Mechanical Engineering Department, Jadavpur University, Kolkata-700032, India, E-mail: nabendu2003_ghosh@yahoo.co.in
}

\begin{abstract}
:
In the present work, dissimilar joints between AISI 409 ferritic stainless steel and AISI 316L austenitic stainless steel were made by gas metal arc welding (GMAW) using ESAB AUTO Rod 316L as a filler wire. Welding was conducted as per the L9 orthogonal array using the Taguchi method. Three levels of the input parameters: welding current, gas flow rate and nozzle to plate distance were selected. After welding, visual inspection and an X-ray radiographic test were conducted on the weld specimens to detect surface and sub-surface defects of weld specimens made from dissimilar stainless steels. The quality of the weld was evaluated in terms of yield strength, ultimate tensile strength and percentage of elongation of the welded specimens. The observed data are interpreted, discussed and analyzed using Taguchi desirability analyses.
\end{abstract}

DOI: $10.1515 / \mathrm{jmbm}-2018-0008$

\section{Introduction}

Gas metal arc welding (GMAW) is an arc welding process in which the source of heat is an arc formed between a consumable metal electrode and the work piece with an externally supplied gaseous shield of an inert gas such as argon and/or helium [1]. The weld quality mainly depends on features of bead geometry, mechanicalmetallurgical characteristics of the weld as well as on various aspects of weld chemistry, and these features are expected to be greatly influenced by various variables such as welding geometry, groove angle, shielding type and mixture [2], and different input parameters: current, voltage, electrode stick-out, gas flow rate, edge preparation, position of welding, welding speed, nozzle to plate distance [3], [4], etc. Moreover, the cumulative effect of various input parameters determines the extent of joint strength that should meet the functional aspects of the weld in the practical field of application [5]. Therefore, preparation of a good quality weld seems to be a challenging job [6], [7], [8], [9]. Dissimilar metal combinations between ferritic stainless steels and austenitic stainless steels (F/A) is in demand in certain applications, and, for example, it is commonly employed in $\mathrm{TiCl}_{4}$ reduction retorts, because austenitic stainless steel has good creep strength and oxidation resistance which are required in the higher temperature regions, while ferritic stainless steel is preferred to avoid the problem of nickel leaching by molten magnesium [10], [11].

Ferritic/austenitic (F/A) joints are a popular dissimilar metal combination used in many applications and these joints have huge demand in industries like petrochemical industries, ship industries, nuclear power plants, pulp and paper, [12], [13], etc. F/A joints are normally produced using conventional welding processes such as manual metal arc (MMA), metal inert gas arc (MIG) and tungsten inert gas arc (TIG) welding [14], [15]. F/A dissimilar joints are based on both technical and economic aspects, i.e. these dissimilar joints can provide satisfactory performance with reasonable cost savings [16], [17]. Joining of dissimilar F/A materials is not an easy task; it is considered to be a challenging problem due to differences in thermal conductivities and thermal expansion which may cause crack formation interfaces [18]. In the present work, dissimilar joints between AISI 409 ferritic stainless steel and AISI 316L austenitic stainless steel, were made by GMAW using ESAB AUTO Rod 316L as a filler wire. Welding has been conducted as per the L9 orthogonal array of the Taguchi method. Three levels of the input parameters: welding current, gas flow rate and nozzle to plate distance, were selected. After welding, a visual inspection and an X-ray radiographic test were conducted on weld specimens, in order to detect surface and sub-surface defects of weld specimens made of dissimilar stainless steels. The quality of the weld was evaluated in terms of yield strength, ultimate tensile strength and percentage of elongation of the welded specimens. The observed data are interpreted, discussed and analyzed using the Taguchi desirability analyses [19], [20], [21], [22]. 


\section{Experimental plan, set-up and procedure}

In the present work, experiments were done in a planned experimental order. The Taguchi orthogonal array design L9 was used as design for the experiment [23], [24]. As mentioned earlier, welding current, gas flow rate and nozzle to plate distance are selected as input parameters and three levels are considered for each of them. Welding process parameters and their levels are shown in Table 1. The welding design matrix as per the L9 Taguchi orthogonal array design is shown in Table 2. The photographic view of the welding set up shown in Figure 1.

Table 1: Welding process parameters and their levels.

\begin{tabular}{lllrrr}
\hline Factors & Unit & Notation & & \multicolumn{2}{c}{ Levels } \\
\cline { 3 - 6 } & & & $\mathbf{1}$ & $\mathbf{2}$ & $\mathbf{3}$ \\
\hline Welding current & $\mathrm{A}$ & $\mathrm{C}$ & 100 & 112 & 124 \\
Gas flow rate & $\mathrm{l} / \mathrm{min}$ & $\mathrm{F}$ & 10 & 15 & 20 \\
Nozzle to plate distance & $\mathrm{mm}$ & $\mathrm{S}$ & 9 & 12 & 15 \\
\hline
\end{tabular}

Table 2: Welding design matrix as per L9 Taguchi orthogonal array design of matrix.

\begin{tabular}{lrr}
\hline Welding current $(\mathbf{C})$ & Gas flow rate $(\mathbf{l} / \mathbf{m i n})(\mathbf{F})$ & Nozzle to plate distance $(\mathbf{m m})(\mathbf{S})$ \\
\hline 1 & 1 & 1 \\
1 & 2 & 2 \\
1 & 3 & 3 \\
2 & 1 & 2 \\
2 & 2 & 3 \\
2 & 3 & 1 \\
3 & 1 & 3 \\
3 & 2 & 1 \\
3 & 3 & 2 \\
\hline
\end{tabular}

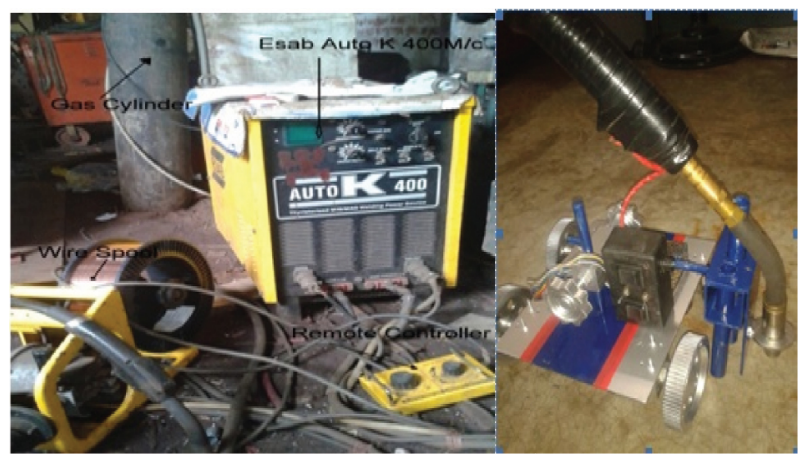

Figure 1: Photographic view of welding set-up.

Dissimilar weld joints between austenitic stainless steel AISI 316L and ferritic stainless steel AISI 409 each of dimension $100 \mathrm{~mm} \times 65 \mathrm{~mm} \times 3 \mathrm{~mm}$ are joined by the MIG welding process by using austenitic filler wire AISI 316 L. No edge preparation is used as it is not recommended for welding of $3 \mathrm{~mm}$ thick austenitic stainless steel. A diameter of the electrode wire is selected at $1.2 \mathrm{~mm}$. The tensile test specimens were tested on a tensile testing machine (INSTRON) as per the ASTM standard. The major specifications of the tensile testing INSTRON machine are as follows: model No.: 5589; serial No.: 95/1058; maximum capacity: $600 \mathrm{KN}$.

A schematic diagram showing the basic dimensions of the tensile test specimens of thickness 3 mm is given in Figure 2. 


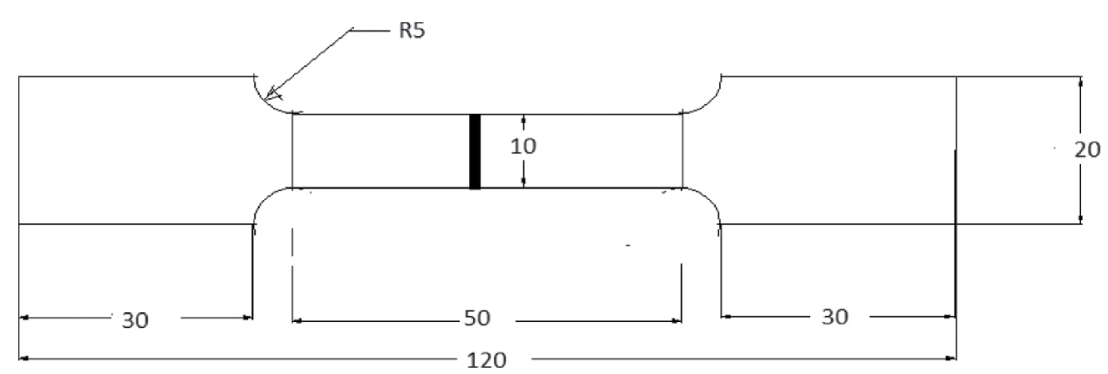

Figure 2: Schematic diagram of the specimen.

\section{Tensile test results and discussion}

The tensile test specimens, prepared corresponding to L9 Taguchi orthogonal array design of experiments, were tested for tensile strengths and the results obtained are given in Table 3. The results shown in Table 3 indicate that for many of the welded samples the test results are satisfactory. The best result was obtained in sample no.7 (ultimate tensile strength $=484.9 \mathrm{MPa}$ ). The worst result in tensile testing was obtained for the sample no. 9. The ultimate tensile strength was $416.5 \mathrm{MPa}$.

Table 3: Tensile tests result.

\begin{tabular}{lrr}
\hline S. No & & Output responses \\
\cline { 2 - 3 } & Yield strength (MPa) & Ultimate tensile strength (MPa) \\
\hline 1 & 304.0 & 430.6 \\
2 & 335.0 & 468.5 \\
3 & 335.9 & 468.7 \\
4 & 264.2 & 481.4 \\
5 & 257.4 & 481.4 \\
6 & 294.1 & 429.1 \\
7 & 246.7 & 484.9 \\
8 & 321.9 & 453.6 \\
9 & 289.7 & 416.5 \\
\hline
\end{tabular}

\section{Desirability function approach}

The literature shows that previous work has explored in great detail the various aspects of modeling, simulation and process optimization in MIG welding. The effect of process parameters on different responses can be analyzed from experimental and analytical research and modeling. The common approaches to tackle modeling and optimization problem in welding include multiple regression analysis, response surface methodology (RSM) and artificial neural networks (ANNs). In most of the cases, the optimization has been performed using a single objective function. For a multi-response process, while applying the optimal setting of control factors, it can be observed that, an increase/improvement of one response may cause change in another response, beyond the acceptable limit. Thus, for solving multi-criteria optimization problem, it is advised to convert multiple objectives into an equivalent single objective function. This may be assumed to be the representative of all the quality characteristics of the product, which needs to be optimized. Taguchi's philosophy is an efficient tool for the design of high quality manufacturing systems. It can reveal the optimal setting by conducting a limited number of experiments. However, the Taguchi method alone cannot solve multi-objective optimization problem. Therefore, the Taguchi method coupled with grey relational analysis is the appropriate option as was found by previous researchers [23], [24].

In the grey-based Taguchi method, a multiple response process optimization problem can be converted to a single response optimization problem where the overall grey relational grade serves as the single objective function or response function to be optimized (maximized).

Optimization using the desirability function (DF) approach is also very helpful in this context. This approach converts each of the responses (objectives) into their individual desirability value, which may vary from zero to 1 . If the response value is beyond the acceptable range, the desirability is assumed to be zero. If it reaches 
the target, the desirability value becomes 1 . Corresponding to each objective, the individual desirability values are then accumulated to compute the overall or composite DF. The common trend is to develop a mathematical model of the composite desirability, in which it is represented as a function of process variables. Optimization is then performed to reveal the combination of factors to achieve maximum overall desirability.

The DF approach is a powerful tool for solving the multiple performance characteristics optimization problems, where all the objectives attain a definite goal simultaneously. The basic idea of this approach is to convert a multiple performance characteristics optimization problem into a single response optimization problem with the objective function of overall desirability. Then the overall DF is optimized. The general approach is to first convert each response $y_{i}$, into an individual DF $d_{i}$, that may vary over the range $0 \leq \mathrm{D}_{\mathrm{i}} \leq 1$, where if the response $y_{i}$ meets the goal or target value, then $d_{i}=1$, and if the response falls beyond the acceptable limit, then $d_{i}=0$. The next step is to select the parameter combination that will maximize overall desirability D

$$
\mathrm{D}=\left(d_{1} \cdot d_{2} \ldots \ldots . d_{m}\right)^{\frac{1}{m}}
$$

where, $m=$ number of responses

To calculate the individual desirability for the corresponding responses using the formula proposed by Derringer and Suich there are three forms of the DFs according to the response characteristics:

The nominal-the-best: The value of $\hat{y}$ is required to achieve a particular target $T$, when the $\hat{y}$ equals $T$, desirability value equals 1 ; if the departure of $\hat{y}$ exceeds a particular range from the target, the desirability value equals 0 , and such a situation represents the worst case. The DF of the nominal best can be written as:

$$
\left\{\begin{array}{c}
\left(\frac{\hat{y}-y_{\min }}{T-y_{\min }}\right)^{S}, y_{\min } \leq \hat{y} \leq T, s \geq 0 \\
\left(\frac{\hat{y}-y_{\min }}{T-y_{\min }}\right)^{t}, T \leq \hat{y} \leq y_{\min }, t \geq 0 \\
0,
\end{array}\right.
$$

where $y_{\max }$ and $y_{\min }$ represent the upper and lower tolerance limits of $\hat{y}$ and $s$ and $t$ represent the indices.

The larger-the-better: The value of $\hat{y}$ is expected to be the larger better. When the $\hat{y}$ exceeds a particular criteria value which can be viewed as the requirement, the desirability value equals 1 ; if the $\hat{y}$ is less than a particular criteria value, which is unacceptable, the desirability equals 0 . The DF of the larger-the-better can be written as

$$
\left\{\begin{array}{cc}
0, & \hat{y} \leq y_{\min } \\
\left(\frac{\hat{y}-y_{\max }}{y_{\max }-y_{\min }}\right)^{r}, & y_{\min } \leq \hat{y} \leq y_{\max } \\
1, & \hat{y}>y_{\max }
\end{array}\right.
$$

The smaller-the-better: The value of $\hat{y}$ is expected to be the smaller the better. When the $\hat{y}$ is less than a particular criteria value the desirability value equals 1 ; if the $\hat{y}$ exceed a particular criteria value, the desirability value equals 0 . The DF of the smaller-the-better can be written as

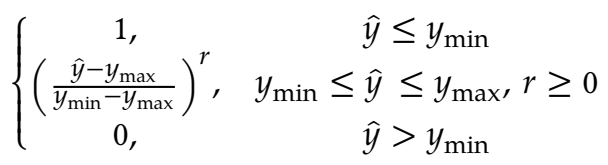

where the $y_{\max }$ and $y_{\min }$ represent the upper and lower tolerance limits of $\hat{y}$ and $r$ represent the weight. The $s, t$ and $r$ in eq. (2), eq. (3) and eq. (4) indicate the weight and are defined according to requirement of the user indices. If the corresponding response is expected to be closer to the target, the weight can be set to the larger value; otherwise, the weight can be set to the smaller value.

\section{Selection of optimum parameters using desirability function analysis}

For the present work the responses should be maximized and hence the larger-the-better formulae is used to find the individual desirability values and are tabulated in Table 4 and using eq. 3, overall desirability values are calculated and tabulated in the Table 5.

Table 4: The individual desirability values. 


\begin{tabular}{lrr}
\hline Sample No. & \multicolumn{1}{c}{ Individual desirability values } \\
\cline { 2 - 3 } & Yield strength (MPa) & Ultimate tensile strength (MPa) \\
\hline 1 & 0.35762 & 0.79386 \\
2 & 0.01009 & 0.23977 \\
3 & 0.00000 & 0.23684 \\
4 & 0.80381 & 0.05117 \\
5 & 0.88004 & 0.05117 \\
6 & 0.46861 & 0.81579 \\
7 & 1.00000 & 0.00000 \\
8 & 0.15695 & 0.45760 \\
9 & 0.51794 & 1.00000 \\
\hline
\end{tabular}

Table 5: Overall desirability values.

\begin{tabular}{lr}
\hline Sample No. & Overall desirability \\
\hline 1 & 0.532823 \\
2 & 0.049186 \\
3 & 0.000000 \\
4 & 0.202808 \\
5 & 0.212207 \\
6 & 0.618294 \\
7 & 0.000000 \\
8 & 0.267993 \\
9 & 0.719680 \\
\hline
\end{tabular}

The response table for the mean overall desirability value is shown in Table 6.

Table 6: Response table for mean overall desirability value.

\begin{tabular}{|c|c|c|c|}
\hline Level & Current & Gas flow rate & Nozzle to plate distance \\
\hline 1 & 0.19400 & 0.24521 & 0.47304 \\
\hline 2 & 0.34444 & 0.17646 & 0.32389 \\
\hline 3 & 0.32922 & 0.44599 & 0.07074 \\
\hline Delta & 0.15043 & 0.26953 & 0.40230 \\
\hline Rank & 3 & 2 & 1 \\
\hline
\end{tabular}

With the help of the response graph for mean overall desirability value (Figure 3) the optimum parametric combination was determined. The optimal factor setting becomes C2F3S1 (i.e. welding current = $112 \mathrm{~A}$, gas flow rate $=201 / \mathrm{min}$ and nozzle to plate distance $=9 \mathrm{~mm}$ ). 


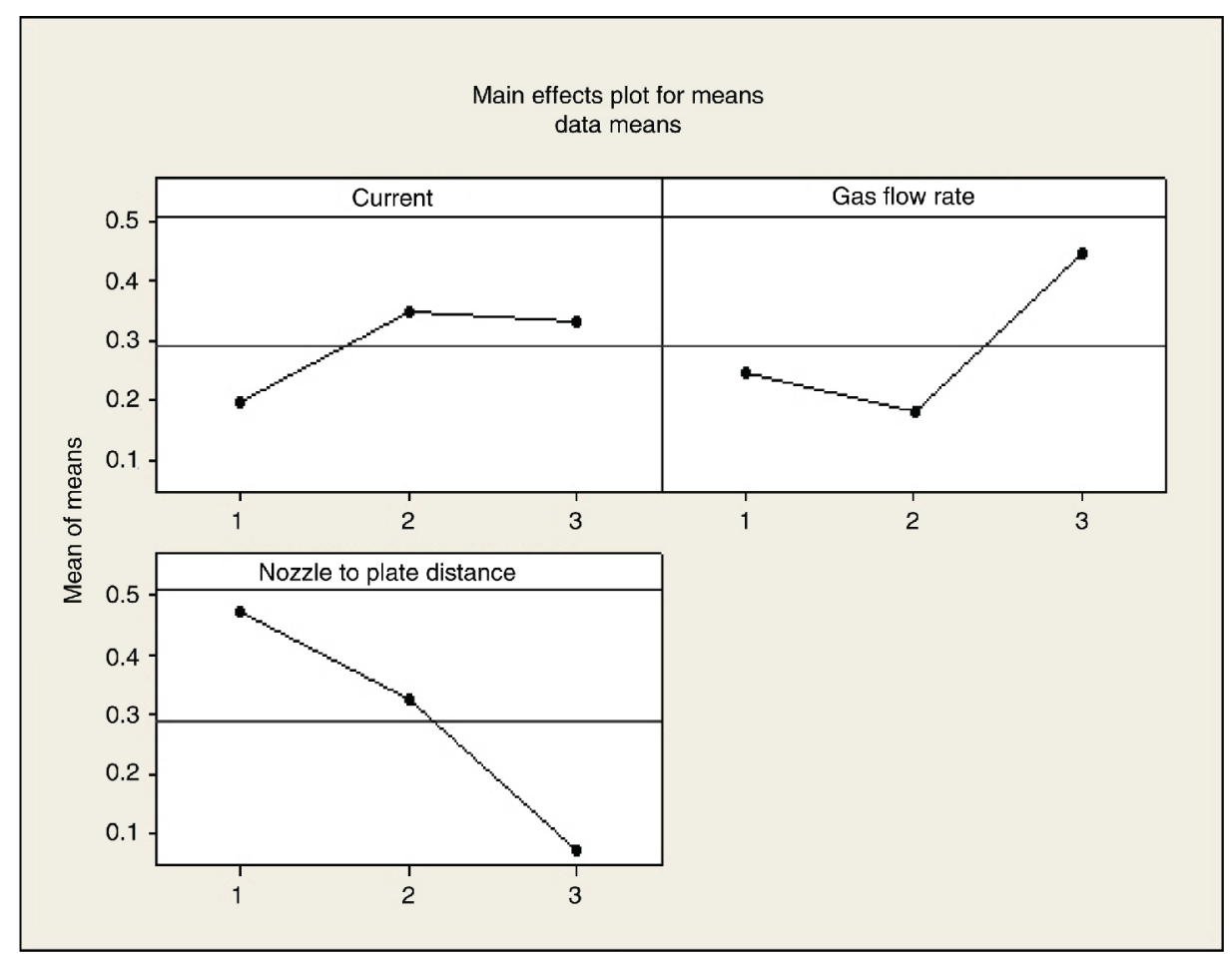

Figure 3: Response graph for mean overall desirability value.

\section{Results of confirmatory test}

A confirmatory test is conducted at optimal parameter combination (C2F3S1) to check the validity of the optimum welding condition. From the results of the confirmatory test (Table 7), it is found that optimum welding parametric condition produced the maximum UTS, this value shows the validation of the proposed optimization methodology.

Table 7: Confirmatory results.

Obtained optimum parametric condition by the Taguchi method

Current (C)

Glass flow rate $(\mathrm{F})$

Nozzle to plate distance $(\mathrm{S})$
Obtained ultimate Tensile strength (U.T.S) by confirmatory test

$112 \mathrm{~A}$

$20 \mathrm{l} / \mathrm{min}$

$9 \mathrm{~mm}$

\section{Conclusions}

- The best result was obtained in sample no.7 (ultimate tensile strength $=484.9 \mathrm{MPa}$ ). The worst result in tensile testing was obtained for the sample no. 9. ultimate tensile strength was $416.5 \mathrm{MPa}$.

- The current was found to be more significant than gas flow rate and nozzle to plate distance in influencing the strength of the joint.

- Optimization of the process parameters was done using the Taguchi desirability methodology; the optimum parametric combination was determined. The optimal factor setting becomes C2F3S1 (i.e. welding current $=112 \mathrm{~A}$, gas flow rate $=20 \mathrm{l} / \mathrm{min}$ and nozzle to plate distance $=9 \mathrm{~mm}$ ). 


\section{Acknowledgment}

The authors sincerely thanks all the staff members of Blue Earth workshop of Jadavpur University who directly or indirectly involved in the experimental work and testing part of this work. The authors are very much grateful to SKB Metallurgical Services, Salkia, Howrah for their cooperation and help.

\section{References}

[1] Rosado LS, Santos TC, Piedade M, Ramos PM, Vilaca P. J. Meas. 2010, 43, 1021-1030.

[2] Tasalloti H, Kah P, Martikainen ]. Int. J. Adv. Manuf. Technol. 2014, 71, 197-205.

[3] Hu B, Yu R, Zou H. NDT\&E Int. 2012, 47, 66-69.

[4] Yilmaz R, Uzun H. J. Marmara Pure Appl. Sci. 2002, 18, 97-113.

[5] Murugan N, Parmar RS. J. Mat. Process. 1994, 41 (4), 381-398.

[6] Kim IS, Basu A, Siores E. Int. J. Adv. Manuf. Technol. 1996, 12 (6), 393-401.

[7] Rao PS, Cupta OP, Murty SN, Rao ABK. Int. ]. Adv. Manuf. Technol. 2009, 45 (5-6), 496-505.

[8] Nagesh DS, Dutta GL. Int. J. Integrated Manuf. 2008, 2, 127-136.

[9] Kim D, Rhee S, Park H. Int. J. Prod. Res. 2002, 40 (7), 1699-1711.

[10] Rakesh C, Riddhish P, Asha I. International Conference on Machine Learning, Electrical and Mechanical Engineering 2014, Jan. 8-9, Dubai (UAE).

[11] Taban E, Deleu E, Dhooge A, Kaluç E. Am. Welding Soc. Welding Res. ]. 2012, 91, 291-297.

[12] Parmar RS. Welding Processes and Technology, 2nd edition. Khanna Publications: New Delhi, 1997.

[13] Khanna OP. Welding Technology. Dhanpat Rai \& Sons: India, 1986.

[14] Tarng YS, Yang WH, Juang SC. Int. J. Adv. Manuf. Technol. 2000, 16, 68.

[15] Chosh A, Mallik AK. Manufacturing Science. East-West Press Private Limited: New Delhi, 2008.

[16] Tarng YS, Juang SC, Chang CH. J. Mater. Process. Technol. 2002, 128, 1-6.

[17] Little RL. Welding and Welding Technology. McGraw Hill Book Company: New York, 1973.

[18] Kim ]K, Hong SC, Kang KB, Kang CY. Met. Mater. Int. 2009, 15 (5), 843-849.

[19] Gunaraj V, Murugan N. J. Mater. Process. Technol. 1999, 88, 266-275.

[20] Juanga SC, Tarnga YS, Liib HR. J. Mater. Process. Technol. 1998, 75 (1), 54-62.

[21] Nagesh DS, Datta GL. J. Mater. Process. Techol. 2002, 123 (2), 303-312.

[22] Kim LS, Park CE, Jeong Y], Son ]S. Int. J. Adv. Manuf. Technol. 18, 98-102.

[23] Juang SC, Tarng YS. J. Mater. Process. Technol. 2002, 122, 33-37.

[24] Lee HK, Han HS, Son K], Hong SB. J. Mater. Sci. Eng. 2006, A415, 149-155. 